\title{
Sea ice-free Arctic during the last interglacial supports fast future loss
}

Article

Accepted Version

Guarino, M.-V., Sime, L. C., Schroeder, D., Malmierca-Vallet, I., Rosenblum, E., Ringer, M., Ridley, J., Feltham, D., Bitz, C., Steig, E. J., Wolff, E., Stroeve, J. and Sellar, A. (2020) Sea ice-free Arctic during the last interglacial supports fast future loss. Nature Climate Change, 10. pp. 928-932. ISSN 1758678X doi: https://doi.org/10.1038/s41558-020-0865-2 Available at https://centaur.reading.ac.uk/91701/

It is advisable to refer to the publisher's version if you intend to cite from the work. See Guidance on citing.

To link to this article DOI: http://dx.doi.org/10.1038/s41558-020-0865-2

Publisher: Nature Publishing Group

All outputs in CentAUR are protected by Intellectual Property Rights law, including copyright law. Copyright and IPR is retained by the creators or other copyright holders. Terms and conditions for use of this material are defined in the End User Agreement.

\section{www.reading.ac.uk/centaur}

\section{CentAUR}


Central Archive at the University of Reading

Reading's research outputs online 


\section{Sea ice-free Arctic during the Last Interglacial supports fast future loss}

Maria-Vittoria Guarino ${ }^{1}$, Louise C. Sime ${ }^{1}$, David Schroeder ${ }^{2}$, Irene Malmierca-Vallet ${ }^{1}$, Erica Rosenblum ${ }^{3}$, Mark Ringer ${ }^{4}$, Jeff Ridley ${ }^{4}$, Danny Feltham ${ }^{2}$, Cecilia Bitz ${ }^{5}$, Eric J. Steig ${ }^{5,6}$, Eric Wolff ${ }^{7}$, Julienne Stroeve $^{3}$, and Alistair Sellar ${ }^{4}$

${ }^{1}$ British Antarctic Survey, Cambridge, UK

${ }^{2}$ Department of Meteorology, University of Reading, Reading, UK

${ }^{3}$ Centre of Earth Observation Science, University of Manitoba, Canada

${ }^{4}$ The Met Office, Exeter, UK

${ }^{5}$ Department of Atmospheric Sciences, University of Washington, US

${ }^{6}$ Department of Earth and Space Sciences, University of Washington, US

${ }^{7}$ Department of Earth Sciences, University of Cambridge, UK

The Last Interglacial (LIG), a warmer period 130-116 ka before present, is a potential analog for future climate change. Stronger LIG summertime insolation at high northern latitudes drove Arctic land summer temperatures 4-5 ${ }^{\circ} \mathrm{C}$ higher than the preindustrial era. Climate model simulations have previously failed to capture these elevated temperatures, possibly because they were unable to correctly capture LIG sea-ice changes. Here, we show the latest version of the fully-coupled UK Hadley Center climate model (HadGEM3) simulates a more accurate Arctic LIG climate, including elevated temperatures. Improved model physics, including a sophisticated sea-ice melt-pond scheme, result in a complete simulated loss of Arctic 
sea ice in summer during the LIG, which has yet to be simulated in past generations of models. This ice-free Arctic yields a compelling solution to the longstanding puzzle of what drove LIG Arctic warmth and supports a fast retreat of future Arctic summer sea ice.

Both land air temperatures and sea surface temperatures in high northern latitudes were considerably warmer during the LIG $(\approx 130000 \text { - } 116000 \text { years before present })^{1-5}$ and global sea level was likely 6-9 $\mathrm{m}$ higher than present ${ }^{6,7}$. Previous climate model simulations of the LIG, forced by appropriate greenhouse gas (GHG) and orbital changes, have failed to capture the observed high temperatures $^{8-11}$. This suggests that these models may not have accurately captured Arctic key climate processes in warmer climates.

Whilst knowledge of past Arctic temperatures is robust thanks to the available observations ${ }^{2,10}$, interpretation of Arctic sea ice changes during the LIG has previously been afflicted by uncertainty ${ }^{8,10,12,13}$. Water-isotope measurements from ice cores have been interpreted to suggest that, alongside the Arctic warming, there was a reduction in mean annual sea ice area ${ }^{8}$. Microfauna in LIG marine sediments recovered from boreholes on the Beaufort Sea Shelf have been interpreted as implying a lack of perennial Arctic sea ice cover ${ }^{14}$, as have planktonic foraminifera recovered from some Arctic marine cores ${ }^{15,16}$. Similarly, ostracodes on the Lomonosov and Mendeleyev Ridges and Morris Jesup Rise have been interpreted as indicative of minimum sea ice coverage during peak LIG warmth ${ }^{17}$. On the other hand, measurements of the recently-developed sea ice proxy IP25 (a carbon-25 highly-branched isoprenoid lipid), when combined with terrestrial and open-water phytoplankton biomarkers, have been interpreted as evidence of perennial LIG ice cover in the central 
part of the Arctic Ocean ${ }^{13}$. Whilst aspects of this particular application of IP25 are debated ${ }^{18}$ this result (see also Methods), along with the fact that no coupled climate models have simulated an ice-free Arctic during the $\mathrm{LIG}^{10,11,13,19}$, has meant that the research community has spent considerable time debating whether or not summer sea ice disappeared during this important past warm $\operatorname{period}^{8,12,13,19}$.

New generation climate models, participating in the Coupled Model Intercomparison Project Phase 6 (CMIP6), constitute to date the most advanced numerical tools we have to investigate the LIG climate. Recent climate models have an Equilibrium Climate Sensitivity (ECS) which is high compared to equivalent previous generation models: the published mean ECS of new CMIP6 models is around 1-2 K higher than for CMIP3-5 models ${ }^{20-23}$. A higher ECS means that the Earth will warm more under a given GHG forcing scenario ${ }^{24-26}$. More specifically, ECS indicates how much warming is expected in response to a doubling of the atmospheric $\mathrm{CO}_{2}$ concentration after the system has reached equilibrium. Despite mechanisms for the higher ECS that are varied and model-dependent, it has been found that the most common cause across CMIP6 models for the increase in ECS is the physical representation of clouds ${ }^{27}$.

Within the CMIP UK model family, the ECS has increased (albeit non-monotonically) from 3.3 K (HadCM3 model) in 2007 to $5.5 \mathrm{~K}$ (HadGEM3 model) in 2019. The rise in the ECS over the decades goes hand-in-hand with a faster predicted loss of Arctic sea ice in the future, prompting questions on the accuracy of climate projections. It is paramount to determine whether the new high-ECS models models yield an improved representation of the Arctic compared to old low-ECS 
models. In this regard, the LIG provides a valuable out-of-sample test case which helps determine if new climate models can realistically simulate warm climate conditions in the Arctic and assess the veracity of current projections of Arctic sea ice decline.

To address this question, we use the latest UK model HadGEM3-GC3.1-N96ORCA1 (henceforth HadGEM3 $)^{28}$ to simulate the LIG. HadGEM3 is a fully coupled atmosphere-land-ocean-ice climate model. The simulation was carried out under the auspices of the CMIP6 model intercomparison project and uses the standard Palaeoclimate Model Intercomparison Project Phase (PMIP4) protocol for the LIG climate ${ }^{29}$ (see Methods for details). In accordance with the PMIP4-CMIP6 guidelines, in HadGEM3 the vegetation is prescribed and consistent with its relative preindustrial (PI) simulation. We also ran an identical simulation using a previous (PMIP3) generation version of the same UK model: HadCM3 ${ }^{30}$. We are interested in comparing the old (CMIP5-PMIP3) and new (CMIP6-PMIP4) generation of UK models in their ability of simulating Arctic surface temperatures and sea ice under warmer-than-present climate conditions. An overview of what has changed between the two model generations is given in Suppl.Table 1.

For both HadGEM3 and HadCM3, sea ice and temperature anomalies are computed against their respective preindustrial simulations (year 1850), and both simulations are evaluated against summertime LIG Arctic temperatures ${ }^{1,2}$.

Our simulation of the LIG with HadGEM3 results in a reduction of Arctic sea ice in all seasons compared to PI, with the greatest decrease during summer (Fig. 1). The LIG sea ice decrease commences in June (when the LIG sea ice extent is outside of the PI range of variability, 
Fig.1a) and culminates in a complete loss of ice by the end of the melt season in August and September (Fig. 1af). The sea ice loss in August and September is robust and persistent, as shown by the small standard deviation of $\sim 0.6$ and 0.4 million $\mathrm{km}^{2}$ respectively, with summer sea ice being present in just $2 \%$ of the summers (Fig. 1a, and below), whereas summer sea ice persists in each year in the HadCM3 simulations (Suppl.Fig. 1).

We compare the results from HadCM3 with our new HadGEM3 simulation by evaluating summer surface air temperature anomalies against a compilation of summer Arctic LIG temperature data ${ }^{1,2,26}$. Note that the observational dataset in use includes peak warmth temperatures throughout the entire Last Interglacial. Whilst the exact timing of this peak warmth has not yet been definitively determined, it seems reasonable to assume that these measurements are approximately synchronous across the Arctic (see Methods for further discussion).

The HadCM3 simulation, in which summer sea ice is persistent, matches only $47 \%$ of the observations within uncertainties (Suppl.Fig. 2 and Suppl.Table 2). In contrast, the ice-free HadGEM3 simulation matches $95 \%$ of the observations (Fig. 2 and Suppl.Table 2). The average LIG temperature anomaly in HadGEM3, for all locations with observations, is $+4.9 \pm 1.2 \mathrm{~K}$ compared with the observational mean of $+4.5 \pm 1.7 \mathrm{~K}(\mathrm{RMSE}=1.5)$. In contrast, the HadCM3 simulation has a clear cold bias with an average temperature anomaly for all sites of $+2.4 \pm 0.9 \mathrm{~K}$ $($ RMSE $=2.7)$, or only about half of the of the observed warming. Additionally, while HadGEM3 qualitatively captures the geographical pattern of Arctic temperature anomalies, HadCM3 is insensitive to the geographical pattern, and does not reach any of the higher observed temperatures (Fig. 
2b). Thus the ice-free HadGEM3 tends to capture both the observed magnitude and the pattern, whilst the ice-present HadCM3 captures neither (Fig. 2ab and Suppl.Fig. 2). From this we deduce that the Arctic was very likely to have been ice-free in summer during the LIG.

Concerning the HadGEM3 simulated mid-latitude temperatures, we point out that these may be higher than some proxy records. However, the validation of LIG temperatures outside the Arctic is beyond the scope of this study and suffers from sparse data records.

Why is summertime sea ice lost in HadGEM3 but not in HadCM3 or in other previous climate-model simulations? The LIG top-of-atmosphere radiative flux north of $70^{\circ} \mathrm{N}$ is $60-75$ $\mathrm{W} \mathrm{m}^{2}$ higher than during the PI in early summer (Fig. 3a). This increase in incoming radiation is well known and has been applied in previous LIG climate-model simulations ${ }^{10,11}$. The crucial aspect is to what extent this increase causes additional melt of sea ice. Snow-covered sea ice has a high albedo, so only a small fraction of the additional incoming shortwave radiation flux causes more melting. The substantial increase of surface net shortwave flux (with maximum value of around $70 \mathrm{~W} \mathrm{~m}^{2}$ in July, Fig.3b) is caused by a decrease of surface albedo. In contrast to previous simulations, HadGEM3 includes a physically-based melt pond model ${ }^{31}$ which significantly modifies the albedo feedback ${ }^{32}$. Sea ice melts because of direct absorption of sunlight and transmission of shortwave radiation through ponded and bare ice to the ocean, which in turn warms. Thus, melt ponds forming in summer months contribute to melting sea ice as more radiation reaches the ocean. This is implicated in a faster rate of summer sea ice melt in HadGEM3 in the LIG compared to the PI. In July, most of the LIG sea ice is already melted or has a concentration smaller than 50\% (Fig. 
1d). By September, all the LIG sea ice is melted (Fig. 1af). The timing of the positive radiation anomaly is of critical importance ${ }^{33}$. By modifying the surface albedo in the Arctic region (via sea ice loss) the system is driven towards a new sea ice-free state that is attained in August-September (Fig. 1a).

We find that clouds over sea ice play little role in determining LIG - PI anomalies in the surface energy balance of the Arctic region. The contribution from the long-wave radiation to the total energy balance anomalies (computed between 70 and $90^{\circ} \mathrm{N}$ ) is almost zero (Fig. 3b). Indeed, north of $70^{\circ} \mathrm{N}$, the Arctic cloud area fraction is almost identical in the LIG and PI HadGEM3 simulations (Suppl.Fig. 9c), while south of $70^{\circ} \mathrm{N}$, the LIG - PI cloud area fraction anomalies are actually negative over the North Atlantic in summer (Suppl.Fig. 9c). Fewer clouds during these summer months allow more solar radiation to reach the ocean, which contributes to the warming of the LIG North Atlantic (Fig. 2a).

Comparing the surface energy budgets north of $70^{\circ} \mathrm{N}$ between HadGEM3 (Fig. 3b) and HadCM3 (Suppl. Fig. 8b) points to a striking difference in July between the two models. In spite of the identical top-of-atmosphere shortwave radiation flux anomalies (Fig. 3a and Suppl.Fig. 8a), the net shortwave radiation flux anomaly at the surface is $40 \mathrm{~W} \mathrm{~m}^{2}$ smaller in HadCM3 (30 W $\mathrm{m}^{2}$ vs. $70 \mathrm{~W} \mathrm{~m}^{2}$ in HadGEM3). This is mainly caused by a smaller surface albedo in HadGEM3 (and to a lesser extent by the differences in cloud fraction). The surface albedo is decreased due to a larger open water and melt pond fraction. Under current climate conditions the maximum pond fraction occurs in mid-July ${ }^{32,34}$. In the LIG simulation the melt season starts earlier with a 
maximum pond fraction reached in mid-June (not shown). This confirms that local thermodynamic processes are responsible for the differences between the two models and that melt pond formation plays a key role in determining how much of the additional top-of-atmosphere shortwave radiation during the LIG can be absorbed by the surface. While HadCM3 does indirectly account for the impact of melt ponds on surface albedo, an explicit melt pond model only exists in HadGEM3 (Suppl.Table 1).

In previous work, the persistence of summer sea ice in the central Arctic during the LIG was linked to a slowdown of the Atlantic Meridional Overturning Circulation (AMOC) ${ }^{13}$. However, over the 200 years of our simulations the AMOC is almost unchanged between the LIG and PI (Suppl.Fig. 11 and 12). Thus the hypothesised compensating mechanism, by which a reduction in northward oceanic heat transport (owing to a weakening of the AMOC) prevents sea ice loss in the central Arctic during the $\mathrm{LIG}^{13}$, does not occur as the LIG and PI heat transport is nearly identical (Suppl.Fig. 13). The HadGEM3 LIG loss of Arctic sea ice is thus a simple direct response to increased net short wave radiation, with no significant compensating changes in clouds or ocean circulation.

The loss of summer sea ice during the LIG has a profound impact on the Arctic and Northern Hemisphere mean surface temperatures year-around (Suppl.Fig. 3). Contrarily to early summer months, the Northern Hemisphere LIG - PI top-of-atmosphere radiative flux anomalies are negative in August, when they attain their lowest value of $-65 \mathrm{~W} \mathrm{~m}^{2}$ (Fig.3a), and autumn, when from September to November anomalies decrease from approximately $-60 \mathrm{~W} \mathrm{~m}^{2}$ to $-10 \mathrm{~W} \mathrm{~m}^{2}$ (Fig.3a). 
This results in a cooling of the Northern Hemisphere during the LIG compared to PI in autumn and winter. The cooling is rapid and strong over land and slower and weaker over the Arctic Ocean (because of the thermal inertia of water masses). HadGEM3 and HadCM3 show remarkably different seasonal patterns of surface temperature anomalies (Suppl.Fig. 5 and 6). In HadGEM3, the Arctic region is much warmer in both autumn (SON) and winter (DJF) during the LIG with maximum positive anomalies of up to $\sim 15 \mathrm{~K}$ in SON and $\sim 7 \mathrm{~K}$ in DJF (Suppl.Fig. 5c and 5d). In HadCM3, where in summer sea ice is present, the autumn warming is much reduced with local regional maxima of $\sim 6 \mathrm{~K}$ and in winter the Arctic ocean largely cools down with weaker positive anomalies of $\sim 2 \mathrm{k}$ (Suppl.Fig. 6c and 6d). In conclusion, because of the loss of summer sea ice, surface air temperature anomalies are much warmer in HadGEM3 than HadCM3 throughout all seasons, mainly over the Arctic Ocean but also over land (Suppl.Fig. 5 and 6).

When considering the significance of our results, two aspects are of particular interest. First, the Arctic sea ice in HadGEM3 historical simulations is too thick compared to present day observations $^{28}$. However, this bias toward thick sea ice in HadGEM3 does not provide protection from complete Arctic summer sea ice loss during the LIG. Indeed, the transition under LIG insolation into a summer sea ice-free (zero multi-year ice) state in HadGEM3 takes around 5 model-years to complete. Once the multi-year sea ice has disappeared in our simulations it does not return. Over 200 years of simulation, the August and September sea ice extent exceeds the ice-free threshold of 1 million $\mathrm{km}^{2}$ only in four and five separate years for September and August respectively (not shown). 
A second aspect of broad significance is the implication of our results for the higher ECS of CMIP6 models. The HadGEM3 climate model has an ECS which is considerably higher than most of its predecessors (see ${ }^{35}$ for details) and, in common with other CMIP6 models, lies outside the CMIP3/CMIP5 ECS range (Fig. 4 and Suppl.Table 3).

Climate models have advanced over the CMIP cycles between 2007 and 2020. By comparing CMIP3 to CMIP6 model simulations, we can show the change in ECS and in when the Arctic is projected to become ice-free under equivalent high-emissions scenarios. We compare standard scenarios where no additional efforts are made to constrain GHG emissions. See Methods for full description. The predicted year of disappearance of September sea ice under high-emissions scenarios is 2086 for HadCM3 (CMIP3/5), 2048 for HadGEM2-ES (CMIP5), and 2035 for HadGEM3 (CMIP6) (Fig. 4). More broadly, multi-model CMIP3-6 mean predictions (and ranges) for a summer sea ice-free Arctic are: CMIP3 2062 (2040-2086), CMIP5 2048 (2020-2081), and CMIP6 2046 (2029-2066) (Fig. 4 and Suppl.Table 3). We note that the latest year of sea ice disappearance for CMIP6 models is 2066 and that $50 \%$ of the models predict sea ice-free conditions between $\sim$ 2030-2040. From this we can see that HadGEM3 is not a particular outlier, in terms of its ECS or projected ice-free year. Thus the 95\% match of our LIG CMIP6-HadGEM3 simulation provides observational support for the HadGEM3 simulation of Arctic conditions, and more broadly supports the simulation of the Arctic sea ice and Arctic climate in high-ECS CMIP6 models. Note however, high model skill in simulating Arctic sea ice retreat, such as that shown here, does not necessarily imply a more accurate simulation of global warming trends. Indeed there is some additional evidence that suggests that high ECS models, whilst producing better simulations of Arctic 
sea ice change, tend to overestimate global warming ${ }^{36}$.

Our study has demonstrated that the high ECS HadGEM3 model yields a much improved representation of Arctic summers during the warmer LIG climate compared to previous old generation model simulations. We analysed simulated surface air temperatures and proxy reconstructions of LIG summer temperatures and showed a 95\% agreement between model and observations. Arctic surface temperatures and sea ice are strongly related ${ }^{37,38}$, by simulating an ice-free summer Arctic our LIG CMIP6 simulation provides (direct) modelling and (indirect) observational support that the summer Arctic could have been ice-free during the LIG. This offers a unique solution to the long-standing puzzle of what occurred to drive the temperatures to rise during LIG Arctic summers. The ability of the HadGEM3 model to realistically simulate the very warm LIG Arctic climate provides independent support for predictions of ice-free conditions by summer 2035. This should be of huge concern to Arctic communities and climate scientists. 


\section{Methods}

\section{1: Observations on Arctic sea ice and sea surface temperature during the LIG. High-}

latitude sea surface and surface air temperatures were warmer during the LIG, suggesting lower summer and winter sea ice cover relative to today ${ }^{3-5}$. Planktonic foraminifers representative of subpolar, seasonally open waters lived in the central part of the Arctic Ocean (measurements from the GreenICE and HLY0503-8JPC cores: Suppl.Fig 14). These measurements point to a LIG Arctic Ocean free of summer sea ice ${ }^{15,16}$. This finding is supported by microfauna found in LIG marine sediments recovered from boreholes on the Beaufort Sea Shelf. These microfauna indicate that more saline Atlantic water was present on the Beaufort Shelf, suggesting a lack of perennial Arctic sea ice during some part of the $\mathrm{LIG}^{14}$. Ostracodes from the Lomonosov and Mendeleyev Ridges and Morris Jesup Rise (Suppl.Fig. 6: NP26-5/32, Oden96/12-1pc and PS2200-5 cores) suggest minimum sea ice cover during the peak of the $\mathrm{LIG}^{17}$. Together this set of observations supports an ice-free (summer sea ice free) Arctic during some part of the LIG.

A reconstruction of LIG Arctic sea ice changes made by combining terrestrial and open-water phytoplankton biomarkers with the sea ice proxy IP25 suggest that while a significant reduction of LIG sea ice occurred across the Barents Sea continental margin (Suppl.Fig 6: PS2138-2 core), the central part of the LIG Arctic Ocean remained ice covered during summer (Suppl.Fig. 6: PS22005, PS51/038-3 and PS2757-8 cores) ${ }^{13}$. Stein et al. (2017) thus supports ice-present conditions throughout the LIG. Stein et al. classify sea ice conditions into seasonal sea ice, ice-free and permanent sea ice; the latter scenario, which is normally linked to the absence (low concentration) of all biomarkers, is however most challenging ${ }^{18}$. An absence of these biomarkers may arise from 
a range of scenarios including degradation in sediments, loss in the water column, or a mixture of these processes ${ }^{39,40}$. Absent/low amounts of IP25 and phytoplankton markers, were associated with permanent sea ice conditions in Stein et al. (2017). However the presence of forams and ostracodes at one site, with co-incident absent/low amounts of IP25, imply that seasonal sea ice may sometimes be misinterpreted as permanent sea ice using this approach. Thus, although there has been much debate on this, actually the bulk of sea ice observations suggest that the Arctic may have been ice-free for some part of the LIG.

1.2: Summertime Arctic air temperature during the LIG. The LIG air temperature observations (Suppl.Table 2) used in this study were previously published ${ }^{1,2}$ and used to assess CMIP5 models ${ }^{26}$. Each observation is of summer LIG air temperature anomaly relative to present day and is located in the circum-Arctic region; all sites are from north of $51 \mathrm{~N}$. There were 7 terrestrial based temperature records; 8 lacustrine records; a further 2 marine pollen-based records; and 3 ice core records included in the original compilation ${ }^{26}$. We add to this an additional new CMIP6-PMIP4 air temperature observation (relative to the past millenium) from the NEEM Greenland ice core ${ }^{4}$, bringing the total number of observations to 21 (Suppl.Table 2). Locations and uncertainties for each observation are provided (Fig. 2; and Suppl.Table 2). Whilst the exact timing of this peak warmth has not yet been definitively determined, and it seems reasonable to assume that these measurements are approximately synchronous across the Arctic, it is not clear that the peak warmth occurs at the same time for the whole of the Northern Hemisphere. Indeed it very unlikely that the peak warmth is synchronous across both hemispheres $\left(\right.$ see $\left.^{3,41}\right)$. The reader is referred to previous reports, and references therein, for a detailed description of each observation ${ }^{1,2,4,26}$. Note that for 
consistency with modelled data, temperature anomalies computed against present day conditions (i.e. 1961-1990 baseline) were corrected to take into account a $0.4 \mathrm{~K}$ of global warming between preindustrial (1850) and present day (1961-1990) conditions $^{42}$. Therefore, our values in Fig. 2, Suppl.Fig. 2 and Suppl.Table 2 differ slightly $(+0.4 \mathrm{~K})$ from the original datasets ${ }^{1,2}$ and represent temperature anomalies relative to the preindustrial era.

2.1 LIG protocol for the simulations. We run Tier 1 LIG simulations, based on the standard CMIP6-PMIP4 LIG experimental protocol ${ }^{29}$. The prescribed LIG (127 ky) protocol differs from the CMIP6 Pre-industrial (PI) simulation protocol in astronomical parameters and the atmospheric trace GHG concentrations. LIG astronomical parameters are prescribed according to orbital constants ${ }^{43}$, and atmospheric trace GHG concentrations are based on ice core measurements. See Suppl.Table 4 for full details ${ }^{29}$. All other boundary conditions, including solar activity, ice sheets, aerosol emissions and etc., are identical to the PI simulation. We run two LIG simulations, one using the UK CMIP6 HadGEM3 model and the other using the CMIP3 HadCM3 model.

2.2 LIG model details. The simulations presented in this study were carried out using the HadGEM3 and HadCM3 climate models. HadGEM3-GC3.1-N96ORCA1 (referred to here as HadGEM3) is the lowest resolution version of the UK CMIP6 physical climate model. It is a global coupled atmosphere-land-ocean-ice model that comprises the Unified Model (UM) atmosphere model ${ }^{44}$, the JULES land surface model ${ }^{44}$, the NEMO ocean model $^{45}$ and the CICE sea ice model ${ }^{46}$. The UM model utilizes a horizontal grid-spacing of approximately $135 \mathrm{~km}$ on a regular latitude-longitude grid. The NEMO model employs an orthogonal curvilinear grid with a $1^{\circ}$ resolution everywhere but near the equator, where it decreases down to $0.33^{\circ}$. The atmosphere and ocean models use 85 
and 75 vertical (pressure) levels respectively.

HadCM3 is the UK CMIP3 coupled atmosphere-ocean general circulation model ${ }^{30}$. Our version of HadCM3 includes the dynamic vegetation model TRIFFID ${ }^{47}$, and the land surface model MOSES $2.1^{48}$. The horizontal resolution of the atmosphere model is $3.75^{\circ}$ longitude by $2.5^{\circ}$ latitude. The ocean model uses a resolution of $1.25^{\circ}$ longitude by $1.25^{\circ}$ latitude. The atmospheric and oceanic components use 19 and 20 vertical levels respectively.

2.3 LIG simulation details. The HadGEM3 PI simulation was initialized using the standard CMIP6 protocol using constant 1850 GHGs, ozone, solar, tropospheric aerosol, stratospheric volcanic aerosol and land use forcing. The PI spin-up was 700 model-years, which allowed the land and oceanic masses to attain approximate steady state. Full details on the PI control simulation are available $^{28,49}$. The LIG simulation was initialized from the end of the spin-up phase of the PI simulation. After initialisation, the LIG was run for 350 model years. This 350 LIG spin-up permits the model to reach atmospheric equilibrium and to achieve an upper-ocean equilibrium. The model was then run for further 200 model-years of LIG production run. This has been demonstrated to be an adequate run length to appropriately capture the model internal variability ${ }^{50}$. The 200 years of production run is the period used for all analysis.

The HadCM3 PI simulation was run for a period of over 600 years. The HadCM3 LIG simulation was initialized from the end of a previous CMIP5 LIG simulation, which was of length 400 years and initiated from the end of the corresponding PI, and run for further 250 years. The total spin-up phase for the HadCM3 LIG simulation used in this study was thus 600 model-years, 
and the length of the production (at atmospheric and upper-oceanic equilibrium) LIG HadCM3 simulation is 50 model-years.

3.1 Analysis of LIG simulations. The simulation results presented in this study use long-term means computed over the entire simulation length. For HadGEM3 the long-term mean is 200 years, for HadCM3 is 50 years. Checks on both show no appreciable drift in the simulations over these periods, and that 50-200 years is sufficient for obtaining reliable simulated air temperature and sea ice numbers in the Arctic region.

For model-observations comparison purposes, the single-point model values in Fig. $2 b$ and Suppl.Table 2 were obtained through nearest-neighbour interpolation on the model grid. Spatial maps of quantities including surface air temperature and sea ice concentration were created by averaging monthly simulation outputs over time. To compute the sea ice seasonal cycle and the surface energy budget of Fig. 2a and 3b, the time average was combined with an area-weighted (to account for the irregularities of the latitude-longitude grid near the poles) spatial average. The sea ice extent was regionally-averaged over the whole Northern Hemisphere, while each term of the surface energy budget was averaged over the Arctic region between $70^{\circ} \mathrm{N}$ and $90^{\circ} \mathrm{N}$.

3.2 Equilibrium Climate Sensitivity (ECS) analysis. The Equilibrium Climate Sensitivity (ECS) data used in Fig. 4 from CMIP3 and CMIP5 models were previously published ${ }^{25,26}$. For CMIP6, the ECS was calculated from the abrupt 4xCO2 idealized emissions experiment for each model using a standard approach ${ }^{51}$. A linear regression of annual-mean anomalies (relative to the PI simulation) in top-atmosphere radiative flux $(\Delta N)$ and surface air temperature $(\Delta T)$ from the first 
150 years of the abrupt $4 \mathrm{xCO} 2$ experiment results in:

$$
\Delta N=F-\lambda * \Delta T
$$

where $F$ is the $4 \mathrm{xCO} 2$ radiative forcing $\left(\mathrm{W} \mathrm{m}^{-2}\right)$ and $\lambda$ is the climate feedback parameter $\left(\mathrm{W} \mathrm{m} \mathrm{m}^{-2} \mathrm{~K}^{-1}\right)^{52}$. This relation is extrapolated to equilibrium (i.e. $\Delta N=0$ ) to obtain the estimate change in surface air temperature $(\Delta T)$ and thus ECS:

$$
\Delta T=E C S=\frac{0.5 * F}{\lambda}
$$

where the multiplicative factor 0.5 indicates that the ECS is defined as the equilibrium warming for a doubling of a $\mathrm{CO} 2$ (rather than a quadrupling).

The abrupt 4xCO2 idealized emissions experiment for each CMIP6 model were downloaded from the Earth System Grid Federation (ESGF), the data repository for all CMIP outputs (see also Data availability section, below).

3.3 Analysis of future sea ice changes. We used 21 st century Arctic sea ice predictions according to the CMIP3 Special Report on Emissions Scenarios (SRES) A1B scenario ${ }^{25}$, the CMIP5 Representative Concentration Pathways (RCP) 8.5 scenario $^{26}$, and the CMIP6 Shared Socioeconomic Pathways (SSP) 5-8.5 scenario $^{53}$. SRESA1B, RCP8.5 and SSP5-8.5 are high-emissions scenarios designed to model potential climate outcomes in the absence of any policy-driven mitigation strategy to tackle global warming. These scenarios differ among each other in how the high GHG 
forcing is achieved (e.g. SRESA1B predicts a very rapid economic and demographic growth but a balance used of fossil and non-fossil energy sources, RCP8.5 predicts high population growth and a mainly coal-based economy, and SSP5-8.5 predicts a high economic growth and a strong reliance on fossil fuels ${ }^{25,26,53}$ ).

To determine the date of future summer sea ice disappearance under these high-emissions scenarios, the first year in which the Arctic September sea ice extent dropped below the threshold value of 1 million $\mathrm{km}^{2}$ for each CMIP3/5/6 model experiment is calculated. Note that for CMIP6, only models currently available on ESGF having monthly sea ice concentration data were used. One ensemble member for each CMIP6 experiment was used.

4. Code availability. The source code of the HadCM3 model and the HadGEM3 model's atmospheric component (UM model) is available under licence. To apply for a licence go to http: // WWw.metoffice.gov.uk/research/modelling-systems/unified-model. JULES is available under licence free of charge, see https: / / jules-lsm.github. io/. The NEMO model code is available from http: //www. nemo-ocean. eu. The model code for CICE can be downloaded from https://code.metoffice.gov.uk/trac/cice/browser.

5. Data availability. CMIP3-6 model data used in this study to compute ECS and ice-free years are available on the Earth System Grid Federation (https : / / esgf-node. Iln . gov/). HadCM3 and HadGEM3 model outputs used to support the findings of this study are available from http: //gws-access.ceda.ac.uk/public/pmip4/vittoria/CMIP6LIG_HadGEM3_CMIP3_ HadCM3 / . HadGEM3 model outputs prepared for CMIP6 can be found at https : / / doi . org/ 
10.22033/ESGF/CMIP 6.41954. The authors declare that all other data are available within the paper and its Supplementary Information. 


\section{Main text references}

1. Kaspar, F., Kühl, N., Cubasch, U. \& Litt, T. A model-data comparison of european temperatures in the eemian interglacial. Geophysical Research Letters 32 (2005).

2. CAPE Last Interglacial Project Members. Last Interglacial Arctic warmth confirms polar amplification of climate change. Quaternary Science Reviews 25, 1382-1400 (2006).

3. Capron, E. et al. Temporal and spatial structure of multi-millennial temperature changes at high latitudes during the last interglacial. Quaternary Science Reviews 103, 116-133 (2014).

4. Capron, E., Govin, A., Feng, R., Otto-Bliesner, B. L. \& Wolff, E. W. Critical evaluation of climate syntheses to benchmark CMIP6/PMIP4 127 ka Last Interglacial simulations in the high-latitude regions. Quaternary Science Reviews 168, 137-150 (2017).

5. Hoffman, J. S., Clark, P. U., Parnell, A. C. \& He, F. Regional and global sea-surface temperatures during the last interglaciation. Science 355, 276-279 (2017).

6. Kopp, R. E., Simons, F. J., Mitrovica, J. X., Maloof, A. C. \& Oppenheimer, M. Probabilistic assessment of sea level during the last interglacial stage. Nature 462, 863-867 (2009).

7. Dutton, A. et al. Sea-level rise due to polar ice-sheet mass loss during past warm periods. Science 349 (2015).

8. Malmierca-Vallet, I. et al. Simulating the Last Interglacial Greenland stable water isotope peak: The role of Arctic sea ice changes. Quaternary Science Reviews 198, 1-14 (2018). 
9. Masson-Delmotte, V. et al. Sensitivity of interglacial Greenland temperature and $\delta^{18} O$ : ice core data, orbital and increased $\mathrm{CO}_{2}$ climate simulations. Climate of the Past 7, 1041-1059 (2011).

10. Otto-Bliesner, B. L. et al. How warm was the last interglacial? New modeldata comparisons. Philosophical Transactions of the Royal Society of London A: Mathematical, Physical and Engineering Sciences 371, 20130097+ (2013).

11. Lunt et al., D. J. A multi-model assessment of last interglacial temperatures. Climate of the Past 9, 699-717 (2013).

12. Sime, L. C. et al. Warm climate isotopic simulations: what do we learn about interglacial signals in greenland ice cores? Quaternary Science Reviews 67, 59-80 (2013).

13. Stein, R., Fahl, K., Gierz, P., Niessen, F. \& Lohmann, G. Arctic Ocean sea ice cover during the penultimate glacial and the last interglacial. Nature communications 8 (2017).

14. Brigham-Grette, J. \& Hopkins, D. M. Emergent marine record and paleoclimate of the last interglaciation along the northwest Alaskan coast. Quaternary Research 43, 159-173 (1995).

15. Nørgaard-Pedersen, N., Mikkelsen, N., Lassen, S. J., Kristoffersena, Y. \& Sheldon, E. Reduced sea ice concentrations in the Arctic Ocean during the last interglacial period revealed by sediment cores off northern Greenland. Paleoceanography 22, PA1218 (2007).

16. Adler, R. E. et al. Sediment record from the western Arctic Ocean with an improved Late Quaternary age resolution: HOTRAX core HLY0503-8JPC, Mendeleev Ridge. Global and Planetary Change 68, 18-29 (2009). 
17. Cronin, T. et al. Quaternary sea-ice history in the arctic ocean based on a new ostracode sea-ice proxy. Quat. Sci. Rev. 29, 3415-3429 (2010).

18. Belt, S. Source-specific biomarkers as proxies for arctic and antarctic sea ice. Org. Geochem. 125, 277-298 (2018).

19. Otto-Bliesner, B. L. et al. Simulating Arctic Climate Warmth and Icefield Retreat in the Last Interglaciation. Science 311, 1751-1753 (2006).

20. Tatebe, H. et al. Description and basic evaluation of simulated mean state, internal variability, and climate sensitivity in miroc6. Geoscientific Model Development 12, 2727-2765 (2019).

21. Wu, T. et al. The beijing climate center climate system model (bcc-csm): the main progress from cmip5 to cmip6. Geoscientific Model Development 12, 1573-1600 (2019).

22. Gettelman, A. et al. High climate sensitivity in the community earth system model version 2 (cesm2). Geophysical Research Letters 46, 8329-8337 (2019).

23. Voldoire, A. et al. Evaluation of cmip6 deck experiments with cnrm-cm6-1. Journal of Advances in Modeling Earth Systems 11, 2177-2213 (2019).

24. IPCC. Climate Change 2001: The Physical Science Basis. Contribution of Working Group I to the Third Assessment Report of the Intergovernmental Panel on Climate Change [Houghton, J.T. Ding, Y. Griggs, D.J. Noguer, M. van der Linden, P.J. Dai, X. Maskell, K. Johnson, C.A. (eds.)]. Tech. Rep., Intergovernmental Panel on Climate Change, Cambridge University Press, Cambridge, United Kingdom and New York, USA. (2001). 
25. IPCC. Climate Change 2007: The Physical Science Basis. Contribution of Working Group I to the Fourth Assessment Report of the Intergovernmental Panel on Climate Change [Solomon, S., D. Qin, M. Manning, Z. Chen, M. Marquis, K.B. Averyt, M.Tignor and H.L. Miller (eds.)]. Tech. Rep. 4, Intergovernmental Panel on Climate Change, Cambridge University Press, Cambridge, United Kingdom and New York, USA. (2007).

26. IPCC. Climate Change 2013: The Physical Science Basis. Contribution of Working Group I to the Fifth Assessment Report of the Intergovernmental Panel on Climate Change. [Stocker, T.F. and Qin, D and Plattner, G and Tignor, $\mathrm{M}$ and Allen, S.K. and Boschung, J and Nauels, A and Xia, Y and Bex, V and Midgley, P.M (eds.)]. Tech. Rep. 5, Intergovernmental Panel on Climate Change, Cambridge, United Kingdom and New York, NY, USA (2013).

27. Zelinka, M. D. et al. Causes of higher climate sensitivity in cmip6 models. Geophysical Research Letters 47, e2019GL085782 (2020).

28. Williams, K. et al. The met office global coupled model 3.0 and 3.1 (gc3. 0 and gc3. 1) configurations. Journal of Advances in Modeling Earth Systems 10, 357-380 (2018).

29. Otto-Bliesner, B. L. et al. The pmip4 contribution to cmip6-part 2: Two interglacials, scientific objective and experimental design for holocene and last interglacial simulations. Geoscientific Model Development 10, 3979-4003 (2017).

30. Gordon, C. et al. The simulation of SST, sea ice extents and ocean heat transports in a version of the Hadley Centre coupled model without flux adjustments. Climate Dynamics 16, 147-168 (2000). 
31. Flocco, D., Schroeder, D., Feltham, D. L. \& Hunke, E. C. Impact of melt ponds on arctic sea ice simulations from 1990 to 2007. Journal of Geophysical Research: Oceans 117 (2012).

32. Schröder, D., Feltham, D. L., Flocco, D. \& Tsamados, M. September arctic sea-ice minimum predicted by spring melt-pond fraction. Nature Climate Change 4, 353 (2014).

33. Perovich, D. K. et al. Increasing solar heating of the arctic ocean and adjacent seas, 19792005: Attribution and role in the ice-albedo feedback. Geophysical Research Letters 34 (2007).

34. Rösel, A. \& Kaleschke, L. Exceptional melt pond occurrence in the years 2007 and 2011 on the arctic sea ice revealed from modis satellite data. Journal of Geophysical Research: Oceans 117 (2012).

35. Andrews, T. et al. Forcings, feedbacks, and climate sensitivity in hadgem3-gc3. 1 and ukesm1. Journal of Advances in Modeling Earth Systems 11, 4377-4394 (2019).

36. Rosenblum, E. \& Eisenman, I. Sea ice trends in climate models only accurate in runs with biased global warming. Journal of Climate 30, 6265-6278 (2017).

37. Mahlstein, I. \& Knutti, R. September arctic sea ice predicted to disappear near 2 c global warming above present. Journal of Geophysical Research: Atmospheres 117 (2012).

38. Stroeve, J. \& Notz, D. Insights on past and future sea-ice evolution from combining observations and models. Global and Planetary Change 135, 119-132 (2015). 


\section{Methods references}

39. Belt, S. T. \& Müller, J. The arctic sea ice biomarker ip25: a review of current understanding, recommendations for future research and applications in palaeo sea ice reconstructions. Quaternary Science Reviews 79, 9-25 (2013).

40. Xiao, X., Stein, R. \& Fahl, K. Mis 3 to mis 1 temporal and lgm spatial variability in arctic ocean sea ice cover: Reconstruction from biomarkers. Paleoceanography 30, 969-983 (2015).

41. Govin, A. et al. Sequence of events from the onset to the demise of the last interglacial: Evaluating strengths and limitations of chronologies used in climatic archives. Quaternary Science Reviews 129, 1 - 36 (2015).

42. Turney, C. S. \& Jones, R. T. Does the agulhas current amplify global temperatures during super-interglacials? Journal of Quaternary Science 25, 839-843 (2010).

43. Berger, A. \& Loutre, M.-F. Insolation values for the climate of the last 10 million years. Quaternary Science Reviews 10, 297-317 (1991).

44. Walters, D. et al. The met office unified model global atmosphere 6.0/6.1 and jules global land 6.0/6.1 configurations. Geoscientific Model Development 10, 1487-1520 (2017).

45. Madec, G. et al. Nemo ocean engine. Institut Pierre-Simon Laplace (2015).

46. Ridley, J. K. et al. The sea ice model component of hadgem3-gc3. 1. Geoscientific Model Development 11, 713-723 (2018). 
47. Cox, P. M. Description of the "triffid" dynamic global vegetation model. Technical Note. Hadley Centre for Climate Prediction and Research, Exeter, UK (2001).

48. Cox, P., Huntingford, C. \& Harding, R. A canopy conductance and photosynthesis model for use in a gcm land surface scheme. Journal of Hydrology 212, 79-94 (1998).

49. Menary, M. B. et al. Preindustrial control simulations with hadgem3-gc3. 1 for cmip6. Journal of Advances in Modeling Earth Systems (2018).

50. Guarino, M. V., Sime, L., Schroeder, D., Lister, G. \& Hatcher, R. Machine dependence and reproducibility for coupled climate simulations: the hadgem 3 -gc 3.1 cmip preindustrial simulation. Geoscientific Model Development 13, 139-154 (2020).

51. Gregory, J. M. et al. A new method for diagnosing radiative forcing and climate sensitivity. Geophysical Research Letters 31 (2004).

52. Gettelman, A., Kay, J. \& Shell, K. The evolution of climate sensitivity and climate feedbacks in the community atmosphere model. Journal of Climate 25, 1453-1469 (2012).

53. O’Neill, B. C. et al. The scenario model intercomparison project (scenariomip) for cmip6. Geoscientific Model Development 9, 3461-3482 (2016).

54. Ridley, J. et al. MOHC HadGEM3-GC31-LL model output prepared for CMIP6. Earth System Grid Federation. https://doi.org/10.22033/ESGF/CMIP6.419 (2018). 
Acknowledgements M.V.G. acknowledges support from NERC research grant NE/P013279/1. L.C.S. acknowledges support through NE/P013279/1, NE/P009271/1, and EU-TiPES. The project has received funding from the European Unions Horizon 2020 research and innovation programme under grant agreement No 820970. D.S. acknowledges support from the NERC-UKESM program. I.M.V. acknowledges support a NERC PhD studentship and EU-TiPES. E.W. is supported by a Royal Society Research Professorship. E.J.S. and C.B. acknowledge support by the US National Science Foundation through NSFGEO-NERC award 1602435. This work used the ARCHER UK National Supercomputing Service (http://www . archer.ac.uk) and the JASMIN data analysis platform (http://jasmin.ac.uk/). In addition, we would like to thank Simon Belt for most helpful discussions on IP25 LIG sea ice interpretations, Bette Otto-Bliesner for providing the published CMIP5 LIG summer temperature observations, and NCAS for supporting the LIG model simulations.

Author Contributions L.C.S and M.V.G contributed equally to the study and are joint first authors for this study. L.C.S oversaw the direction and formulation of the research. M.V.G. carried out the HadGEM3 simulations and analysed all simulation results. D.S. helped guide the interpretation of simulation results. I.M.V. ran the HadCM3 simulations. E.R. helped with the CMIP3-6 projected sea-ice-free analysis. M.R. computed CMIP6 ECS data. J.R. assisted HadGEM3 data post-processing. All authors have read the manuscript and provided comments. L.C.S and M.V.G. wrote the manuscript.

Competing Interests The authors declare that they have no competing financial interests.

Correspondence Correspondence and requests for materials should be addressed to L.C.S. and M.V.G.(email: lsim@bas.ac.uk, marino@bas.ac.uk). 
Figure 1 Annual cycle and sea ice concentration maps for the Last Interglacial and Preindustrial simulations. (a) Shows the HadGEM3 simulated mean seasonal cycle of sea ice extent for PI (blue line) and LIG (orange line). The shaded areas represent \pm two times the standard deviation, and the dashed lines are the maximum and minimum sea ice extent for each month over the 200-year period. 200-year means of sea ice concentration from the LIG (left) and PI (right) simulation in March (b,c), July (d,e) and September $(\mathfrak{f}, \mathrm{g})$.

Figure 2 Comparison of observed and simulated temperatures for the Last Interglacial. Modelled HadGEM3 summer (JJA) LIG - PI surface air temperature anomalies overlain by observed summer temperature anomalies. The scatter plot shows HadGEM3 (orange circles) and HadCM3 (green diamonds) model data versus observations, the error-bars represent one standard deviation on either side of the observational estimate. The correlation coefficient computed using linear regression analysis is 0.6 for HadGEM3 and 0.2 for HadCM3. See Suppl. Table 2 for observational data.

Figure 3 Last Interglacial minus Preindustrial top-of-atmosphere radiative forcing and surface energy balance anomalies. (a) Monthly zonal-mean LIG - PI anomalies of the Top of Atmosphere (TOA) short-wave incoming radiation. (b) LIG - PI anomalies for each term of the surface energy budget computed between $70 \mathrm{~N}$ and $90 \mathrm{~N}$. Net surface heat flux, short-wave and and long-wave radiation components, and the sensible and latent heat fluxes are shown. 
Figure 4 Equilibrium climate sensitivity and year of September sea ice disappearance for CMIP3, CMIP5 and CMIP6 models. ECS is shown in red (lines), sea ice-free year in blue (circles). Stars show results for each CMIP generation of the UK model, the yellow star is the UK CMIP6 model HadGEM3. For CMIP6 models having same date of sea ice disappearance (2038), an offset of one year was used for visibility. Note that only models for which both ECS and ice-free year is known are shown. See Suppl.Table 3 for all values. 

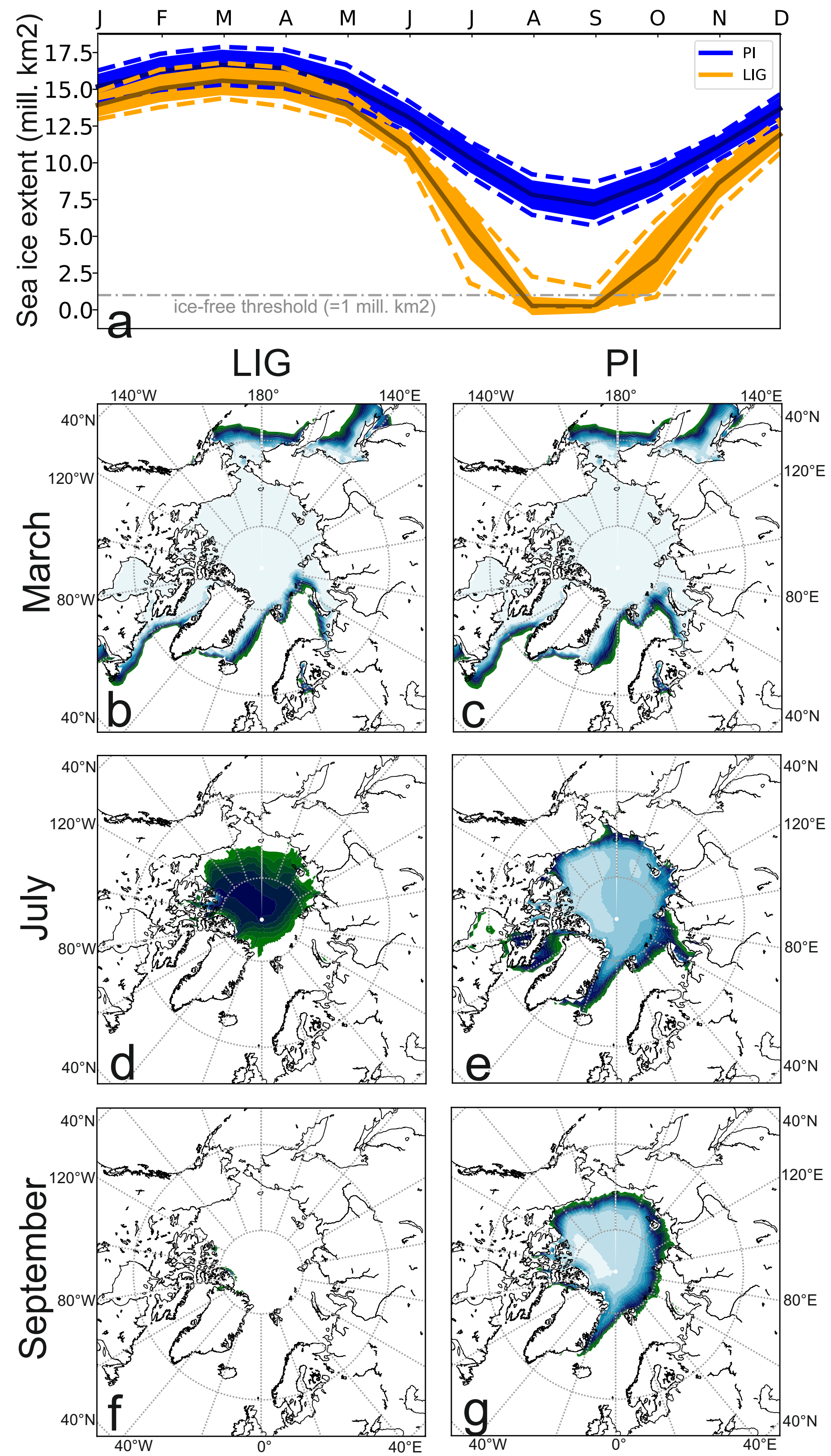
0.15
0.25
0.35
$\begin{array}{llll}0.45 & 0.55 & 0.65 & 0.75\end{array}$
$0.85 \quad 0.95$ 


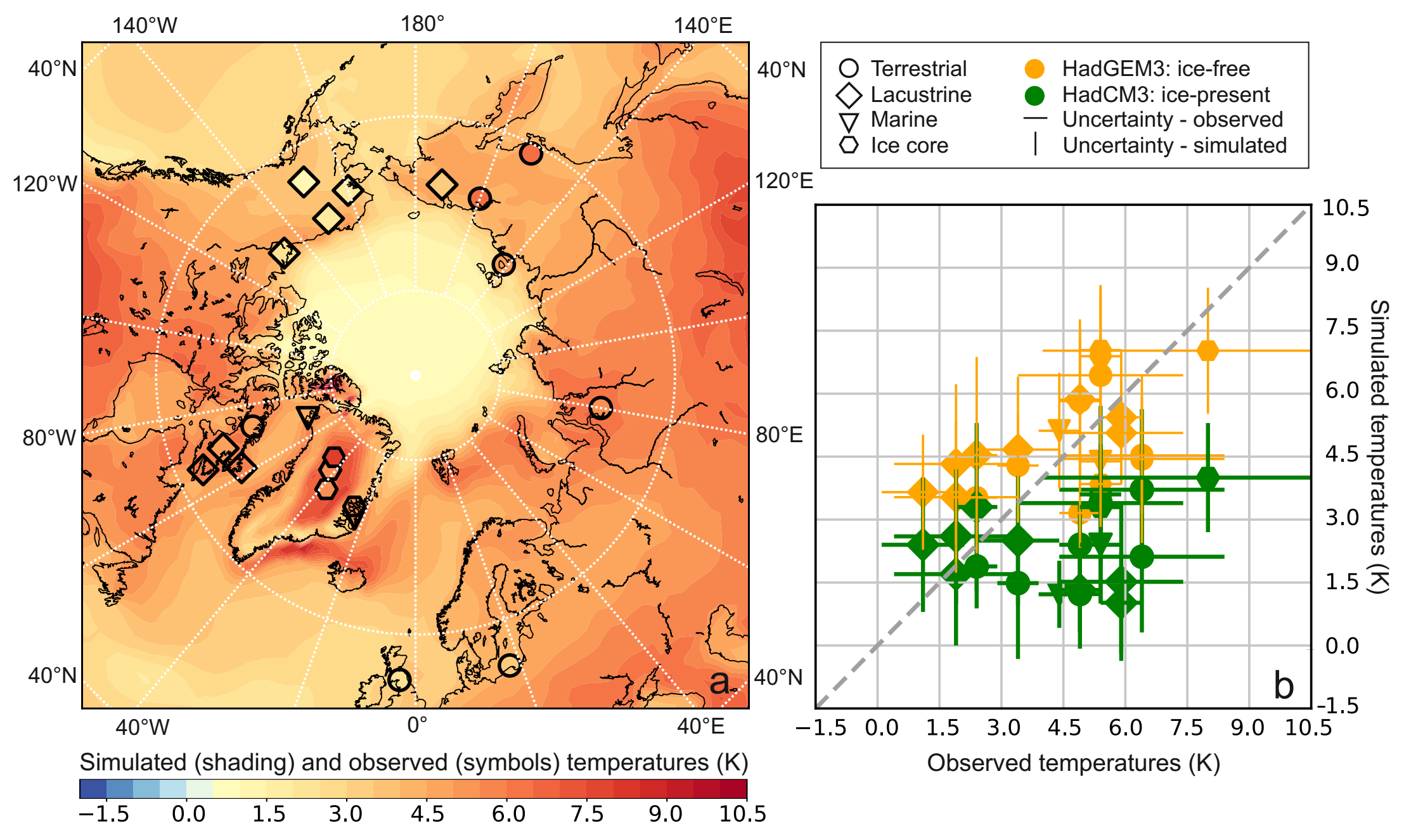




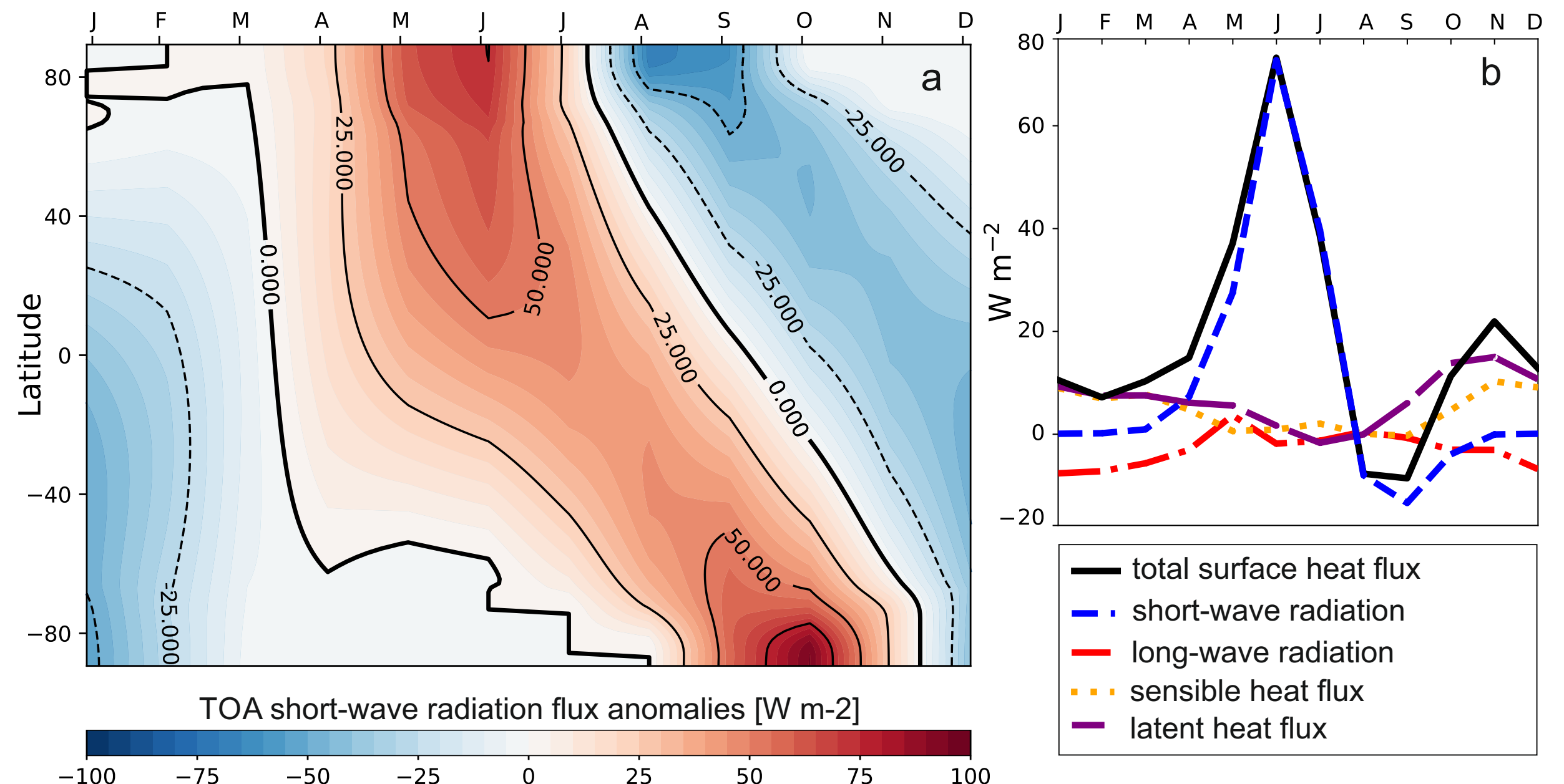




\begin{tabular}{|c|c|c|c|}
\hline Figure \# & $\begin{array}{l}\text { Figure title } \\
\text { One sentence only }\end{array}$ & $\begin{array}{l}\text { Filename } \\
\text { This should be the } \\
\text { name the file is saved as } \\
\text { when it is uploaded to } \\
\text { our system. Please } \\
\text { include the file } \\
\text { extension. i.e.: } \\
\text { Smith_ED_Fi_1.jpg }\end{array}$ & $\begin{array}{l}\text { Figure Legend } \\
\text { If you are citing a reference for the first time in these legends, } \\
\text { please include all new references in the Online Methods References } \\
\text { section, and carry on the numbering from the main References } \\
\text { section of the paper. }\end{array}$ \\
\hline Extended Data Fig. 1 & NA & & \\
\hline Extended Data Fig. 2 & NA & & \\
\hline Extended Data Fig. 3 & NA & & \\
\hline Extended Data Fig. 4 & NA & & \\
\hline Extended Data Fig. 5 & NA & & \\
\hline Extended Data Fig. 6 & NA & & \\
\hline Extended Data Fig. 7 & NA & & \\
\hline Extended Data Fig. 8 & NA & & \\
\hline Extended Data Fig. 9 & NA & & \\
\hline Extended Data Fig. 10 & NA & & \\
\hline
\end{tabular}

\section{Supplementary Information:}

\section{A. Flat Files}

\begin{tabular}{|l|l|l|l|}
\hline Item & Present? & $\begin{array}{l}\text { Filename } \\
\text { This should be the name } \\
\text { the file is saved as when it }\end{array}$ & $\begin{array}{l}\text { A brief, numerical description of file contents. } \\
\text { i.e.: Supplementary Figures 1-4, Supplementary Discussion, and } \\
\text { Supplementary Tables 1-4. }\end{array}$ \\
\hline
\end{tabular}




\begin{tabular}{|l|l|l|l|}
\hline & & $\begin{array}{l}\text { is uploaded to our system, } \\
\text { and should include the file } \\
\text { extension. The extension } \\
\text { must be .pdf }\end{array}$ & \\
\hline Supplementary Information & Yes & $\begin{array}{l}\text { nature_paper_suppleme } \\
\text { ntary_Jun2020.pdf }\end{array}$ & Supplementary Figures 1-14, and Supplementary Tables 1-4 \\
\hline Reporting Summary & Choose an item. & \multicolumn{2}{|c|}{} \\
\hline
\end{tabular}

\section{B. Additional Supplementary Files}

12

\begin{tabular}{|l|l|l|l|}
\hline & $\begin{array}{l}\text { Number } \\
\text { If there are multiple files of the same } \\
\text { type this should be the numerical } \\
\text { indicator. i.e. "1" for Video 1, "2" for } \\
\text { Video 2, etc. }\end{array}$ & $\begin{array}{l}\text { Filename } \\
\text { This should be the name the file is } \\
\text { saved as when it is uploaded to our } \\
\text { system, and should include the file } \\
\text { extension. i.e.: Smith_ } \\
\text { Supplementary_Video_1.mov }\end{array}$ & $\begin{array}{l}\text { Legend or Descriptive Caption } \\
\text { Describe the contents of the file }\end{array}$ \\
\hline Choose an item. & NA & & \\
\hline Choose an item. & NA & & \\
\hline Choose an item. & NA & & \\
\hline Choose an item. & NA & & \\
\hline Choose an item. & NA & & \\
\hline Choose an item. & NA & & \\
\hline
\end{tabular}

14

\section{Source Data}

\begin{tabular}{|l|l|l|}
\hline $\begin{array}{l}\text { Parent Figure or } \\
\text { Table }\end{array}$ & $\begin{array}{l}\text { Filename } \\
\text { This should be the name the file is saved as } \\
\text { when it is uploaded to our system, and } \\
\text { should include the file extension. i.e.: } \\
\text { Smith_SourceData_Fig1.xIs, or Smith_ }\end{array}$ & $\begin{array}{l}\text { Data description } \\
\text { e.g.: Unprocessed Western Blots and/or gels, Statistical Source } \\
\text { Data, etc. }\end{array}$ \\
\hline
\end{tabular}




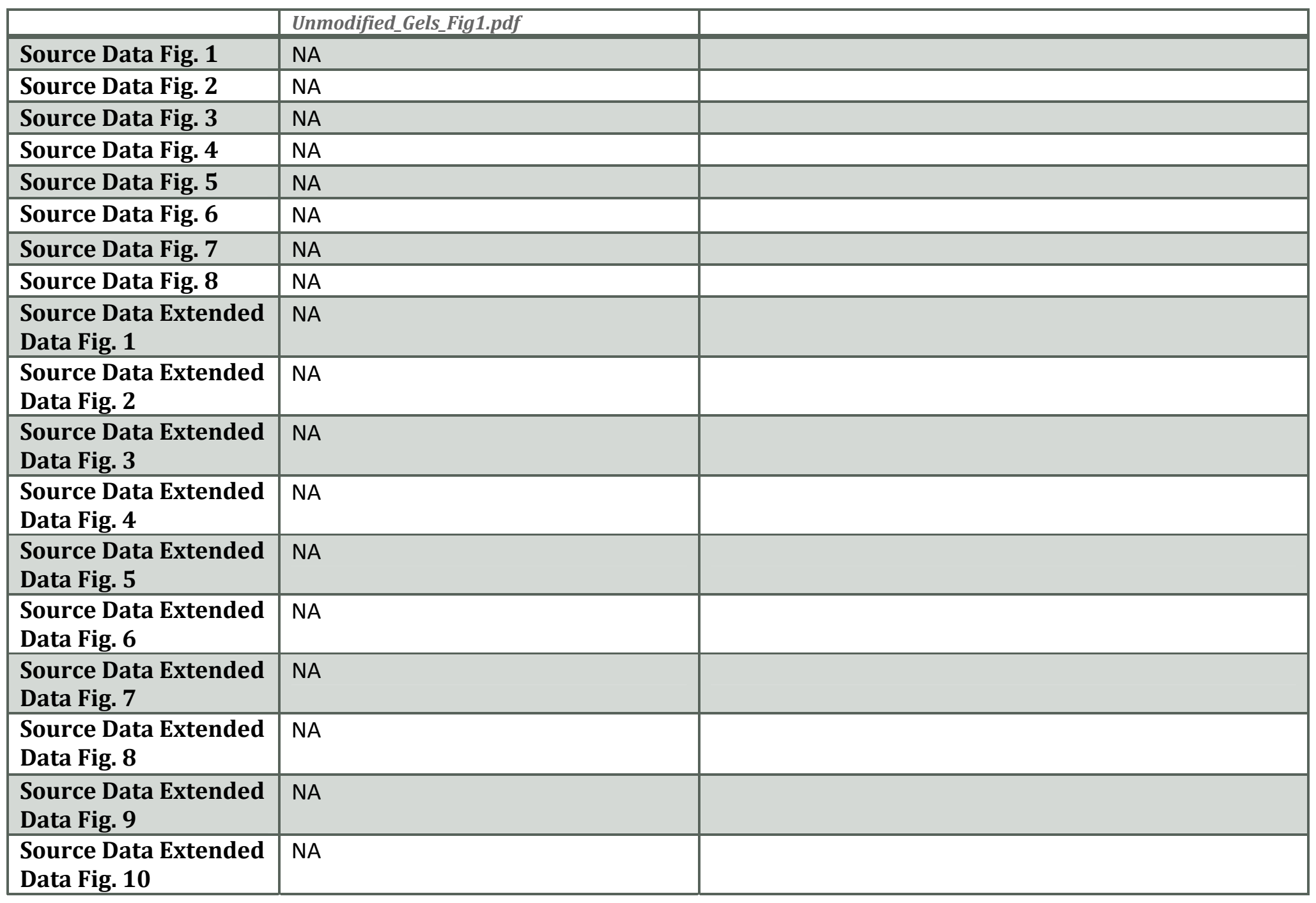

